\title{
Does Growth Stunting Correlate with Oral Health in Children?: A Systematic Review
}

\author{
Zayyana Jasmine Sadida ${ }^{1} \quad$ Ratna Indriyanti ${ }^{2} \quad$ Arlette Suzy Setiawan ${ }^{2, \odot}$ \\ ${ }^{1}$ Faculty of Dentistry, Universitas Padjadjaran, Jl. Sekeloa Selatan 1, \\ Address for correspondence Arlette Suzy Setiawan, Department of \\ Bandung, Indonesia \\ 2Department of Pediatric Dentistry, Faculty of Dentistry, Universitas \\ Padjadjaran, Jl. Sekeloa Selatan 1, Bandung, Indonesia \\ Pediatric Dentistry, Faculty of Dentistry, Universitas Padjadjaran, Jl. \\ Sekeloa Selatan 1, Bandung 40132, Indonesia \\ (e-mail: arlette.puspa@fkg.unpad.ac.id).
}

Eur J Dent 2022;16:32-40.

\begin{abstract}
Growth stunting is when children tend to be shorter than their peers through the World Health Organization child growth standard measurement. The condition may affect the development of the brain and other parts of the body, including the oral cavity, which manifests in oral hygiene and overall oral health. This systematic approach literature study aimed to evaluate the correlation between growth stunting and oral health in children. This study was conducted by using a literature review method with a systematic approach by searching for articles related to research topics on PubMed and Google Scholar. The search was adjusted to the inclusion category, which is research that discusses malnutrition and oral health published between 2010 and 2020-research conducted on boys and girls-from birth to 18 years. The exclusion categories used were articles that did not discuss growth stunting and oral health, and grey literature was excluded. The selection of articles was carried out by using the Preferred Reporting Items for Systematic Reviews and Meta-Analyses (PRISMA) approach and resulted in 10 selected articles with details as follows: the correlation between growth stunting and oral health in three articles. A high plaque index in growth stunting children was found in two articles, and a decrease in saliva composi-

Keywords

- growth stunting

- oral hygiene

- salivary flow rate

- plaque

- malnutrition

- dental caries tion in growth stunting children was also found in two articles. Four articles showed a relationship between growth stunting and salivary flow rate. Lastly, one article showed the relationship between growth stunting and the incidence of dental caries. Despite the limitation of the review, the correlation between growth stunting and overall oral health in children can be seen through the oral hygiene index as moderate to low, high plaque index, decreased salivary flow rate, salivary composition, and dental caries in children with growth stunting.
\end{abstract}

\section{Introduction}

Growth stunting is a form of growth failure in the body and brain in children caused by long-term malnutrition or recurrent infections so that children tend to be shorter than their peers and have delays in thinking processes. ${ }^{1}$ Stunting can be

published online October 1, 2021
DOI https://doi.org/

$10.1055 / \mathrm{s}-0041-1731887$ ISSN 1305-7456 measured based on the World Health Organization (WHO) child growth standards median standard deviation with body height measurement to age $(\mathrm{TB} / \mathrm{U})$ indicator, namely if the Z-score value is $\mathrm{TB} / \mathrm{U}<-2 \mathrm{SD} .^{2} \mathrm{~A}$ total of approximately $21.9 \%$ or 149 million children under 5 years of age in the world are stunted, with 25\% found in Southeast Asia. ${ }^{3}$ Indonesian Basic

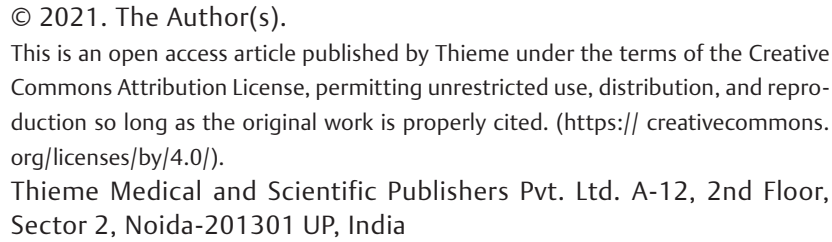


Health Research in 2018 states that the prevalence of growth stunting in Indonesia is $30.8 \%$. This prevalence indicates a decrease of $6.4 \%$ compared to the prevalence in 2013 (37.2\%). ${ }^{4}$

Clinical manifestations of growth stunting generally affect motoric and mental development. ${ }^{5}$ Whereas in the oral cavity, stunting manifests as a lack of resistance to microbial biofilms and decreased salivary flow rate..$^{6,7}$ This manifestation can affect a person's oral health, which has a vital role in the quality of life of a child and provides an overview of general health until the child grows up., ${ }^{8,9}$ Poor oral hygiene will lead to dental and oral health problems. ${ }^{8}$ Based on Basic Health Research Data in 2018, the proportion of dental and oral health problems in Indonesia is $57.6 \%$, which means it is still relatively high. ${ }^{10}$

Caries and other oral diseases may develop from plaque deposits that resulted from the inability of a child to brush their teeth due to inadequate psychomotor development. Problems in psychomotor development are often seen as the later effects of growth stunting. ${ }^{11}$ The formation and adhesion of plaque biofilm can be prevented by the components in saliva, causing a salivary flow to have an essential role in preventing the adherence of bacteria to the teeth and oral mucosal surfaces. ${ }^{12}$ Singh et al states a decrease in salivary flow rate in chronically malnourished children (growth stunting), both stimulated and unstimulated. ${ }^{13}$ This inhibition of salivary flow is caused by atrophy of the salivary glands associated with protein deficiency (protein energy malnutrition) and vitamin A, thereby reducing the cavity defense capacity against infection buffering ability against plaque acid. This condition may also affect the amount and composition of Saliva, limiting the protective effect in the oral cavity, thereby affecting one's oral health. This review evaluates a correlation between growth stunting and oral health in children with growth stunting experience.

\section{Methods}

\section{Primary Outcome}

The primary outcome of this systemic review is to evaluate the correlation between growth stunting and oral health in children aged up to 5 years old with a history of stunting.

\section{Inclusion/Exclusion Criteria}

The eligibility criteria were defined by a selection of articles in inclusion and exclusion criteria. The articles were identified as already in the correct population, using appropriate interventions, and relevant to the research topic. ${ }^{14}$ After all relevant articles were submitted and duplicated removed, titles and abstracts from all remaining articles were screened manually to remove articles that did not meet the inclusion criteria. References from included articles needed to be checked to identify other relevant studies that could be re-entered based on predefined inclusion criteria. ${ }^{15}$

Articles that report a study that did not examine the association of stunting with oral health in children were excluded. Materials and research produced by an organization outside of the traditional commercial or academic publishing and distribution channels were also excluded; these articles were known as grey literature. Common grey literature publication types include reports (annual, research, technical, project), working papers, or government documents. ${ }^{16}$

\section{Search Strategy and Study Selection}

A comprehensive search of the PubMed and Google Scholar databases from its inception to December 2020 was conducted to identify studies that evaluated the main topic of this systematic review. The search was carried out by using keywords or MESH terms and the article text for the following search terms: ("stunting"), ("chronic malnutrition"), ("malnutrition"), and ("oral health)." These keywords were then used together with the Boolean operators (OR and AND) to combine the search. The filters used in PubMed were the publication year filter, which is 2010 to 2020 , and the age filter for children (0-18 years), while the filters used in Google Scholar were the year of publication filter within the same period.

The articles resulting from this search were screened manually-first based on the title, then the abstract, and finally, the complete manuscript-to determine their appropriateness for inclusion in the literature review. References cited in the included articles were also reviewed to identify additional published articles not identified by the database search.

\section{Data Extraction}

Selected publications were independently reviewed by two investigators (Z.J. and R.A.). The extracted data included information about the study design characteristics, group, and subjects characteristics. The data also include the author's name, country, year of publication, keywords, research method, sample, assessment, research results, conclusions, and the quality level of each article. Disagreements between the authors were resolved through consensus.

Quality assessment of all included articles was performed independently by a reviewer as part of the data extraction process. Quality assessment or critical appraisal is a systematic assessment and interpretation of research results to consider the validity, results, and relevance of research. ${ }^{17}$ The quality assessment used in this study is the National Institutes of Health (NIH) quality assessment tool. ${ }^{18}$ Reviewers used the study rating tools on the range of items included in each tool to judge each study to be of "good," "fair," or "poor" quality. The ratings on the different items were used by the reviewers to assess the risk of bias in the study due to flaws in study design or implementation. In general terms, a "good" study has the least risk of bias, and results are considered to be valid. A "fair" study is susceptible to some bias deemed not sufficient to invalidate its results. The fair quality category is likely to be broad, so studies with this rating will vary in their strengths and weaknesses. A "poor" rating indicates significant risk of bias. Studies rated poor were excluded from the body of evidence to be considered for each check question (CQ). The only exception allowed was if there was no other evidence available, then poor quality studies could be considered. However, this exception was not applied in this project because there were no situations found where only 
poor quality studies were available for a body of evidence for a particular CQ. ${ }^{19}$

The quality of the reported information included in each article was assessed by following the Preferred Reporting Items for Systematic Review and Meta-analyses (PRISMA).

\section{Results}

\section{Studies Included}

The study selection process for inclusion in the review is summarized in - Fig. 1. The database search strategy identified 619 potentially eligible references, which resulted in 500 after multiple article dumping. After screening titles and abstracts, 22 full-text articles were reviewed in their entirety. Twelve articles were excluded because of the following reasons; merely discuss nutrition in general $(n=2)$, describe the body mass index (exclusion category; $n=2$ ), exceed the inclusion age criteria, do not mention the state of oral health $(n=4)$, grey literature, and do not directly associate growth stunting with oral health $(n=2)$. Eventually, 10 articles were included in the literature research (-Table $\mathbf{1}$ ).

\section{Description of the Study Characteristics}

The total number of articles that have been selected and reviewed is ten articles with variable study designs and quality. No meta-analysis was performed because of the heterogeneity of the identified studies. The population of the studies varied from 60 to 914 children depending on the article. Moreover, the types of studies were different: eight studies used a cross-sectional study design, ${ }^{20-28}$ and one cohort study. ${ }^{29}$ There were also different types of the parameter used to analyze oral health. While some authors use Oral Hygiene Index-Simplified (OHI-S), ${ }^{23,28,29,}$ some others use dental plaque index (Silness and Löe) and or dental calculus index (Greene and Vermillion). ${ }^{26,27}$ Dental caries, as the most common oral disease, was also a parameter for defining oral health mention by one author. ${ }^{28}$ Salivary flow rate also seen used by authors to measure oral health. .1,22,30,31 $^{2}$

Assessing the quality of evidence contained within a systematic review is as important as analyzing the data within. $\mathrm{NIH}$ quality assessment tool, as shown in - Table 1 revealed that four articles were of good quality, 22,27,32,33 two other articles were in the fair category, ${ }^{13,20,}$ while four articles were of poor quality or had high potential for bias. ${ }^{7,23,24,31}$

\section{Discussion}

The correlation between growth stunting and oral health seems quite evident, and there is significant scientific evidence that points to this direction. In this study, oral health

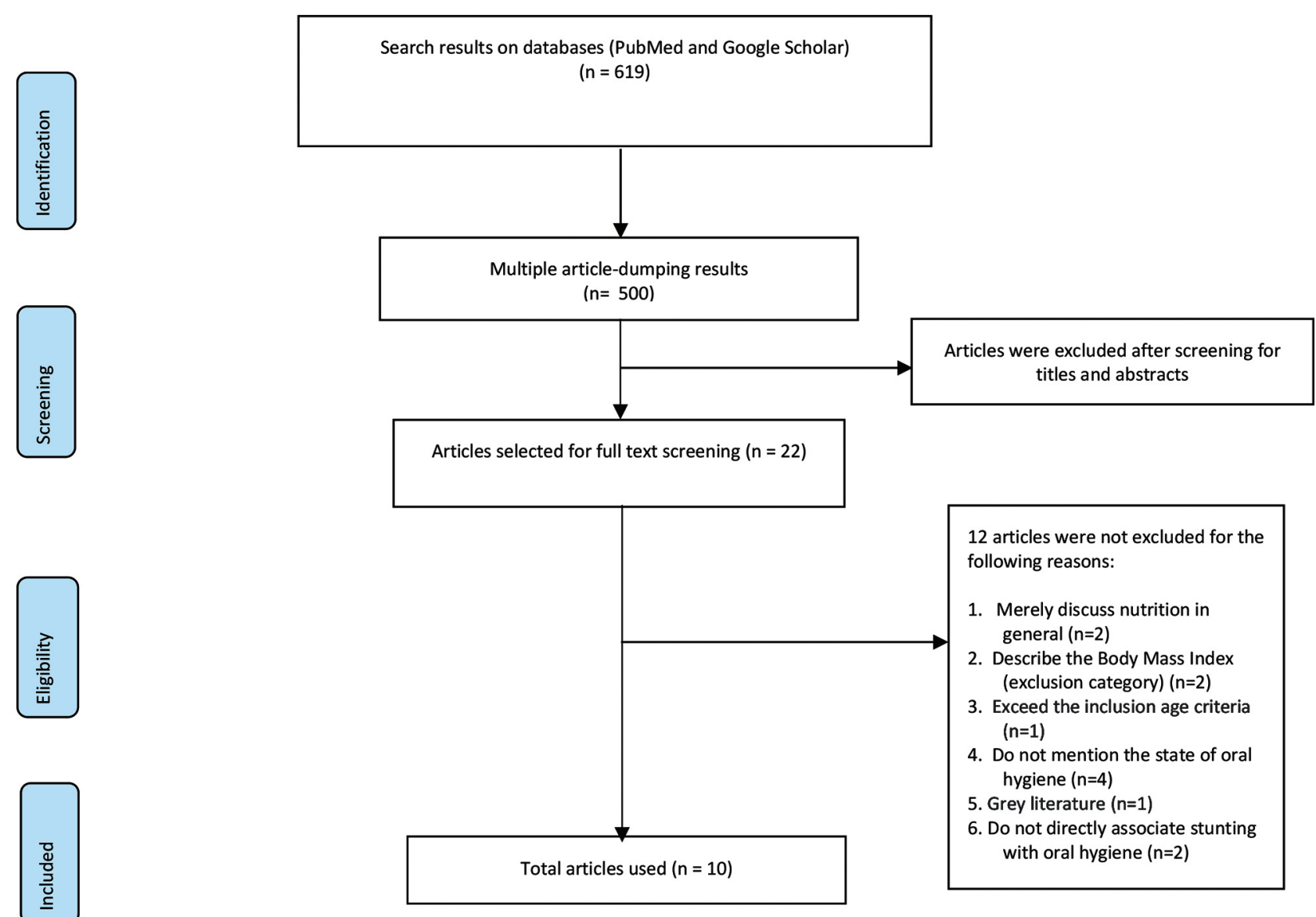

Fig. 1 Preferred Reporting Items for Systematic Reviews and Meta-Analyses flow chart of literature search and review. 
Stunting and Oral Health in Children Sadida et al. 35

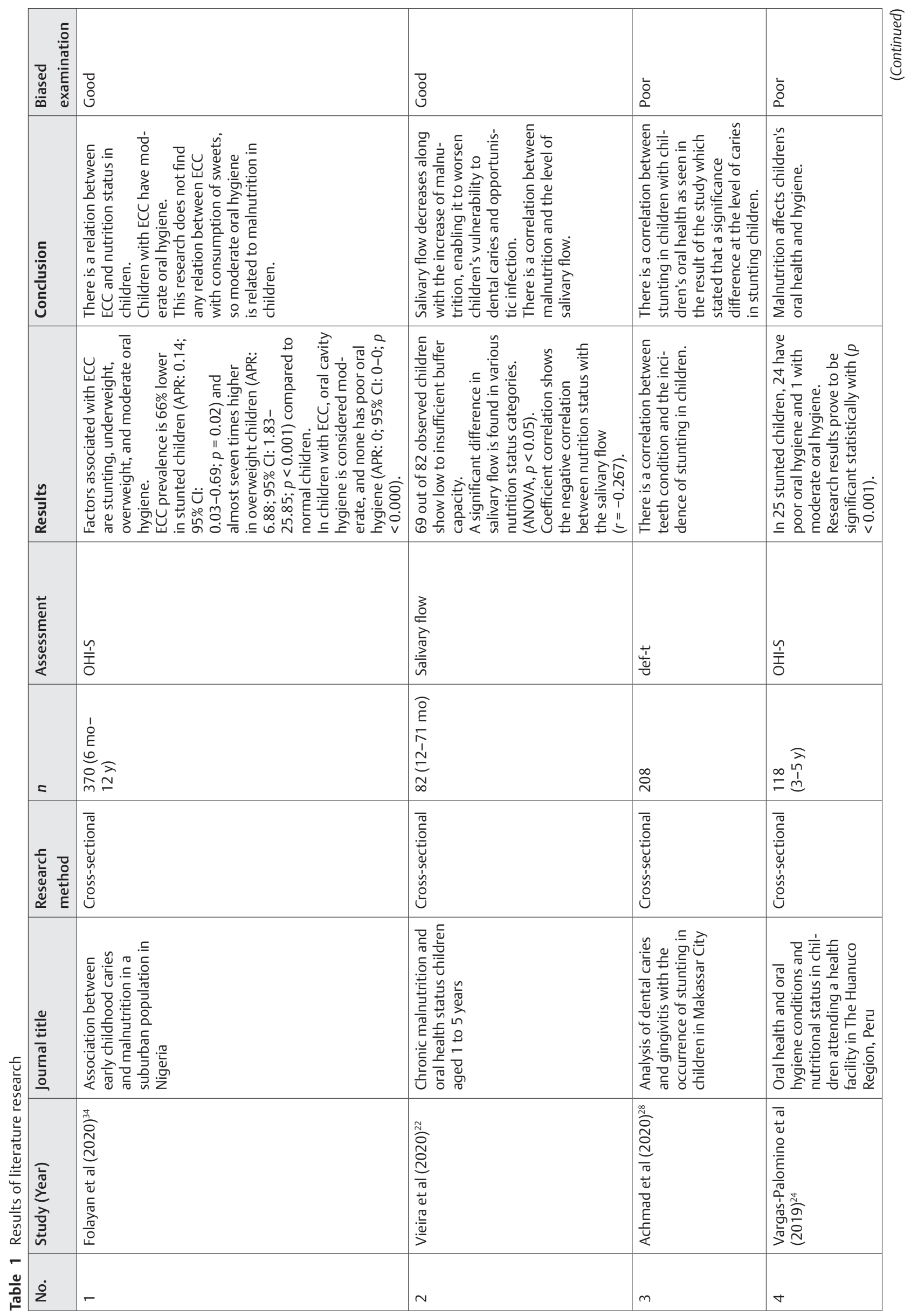




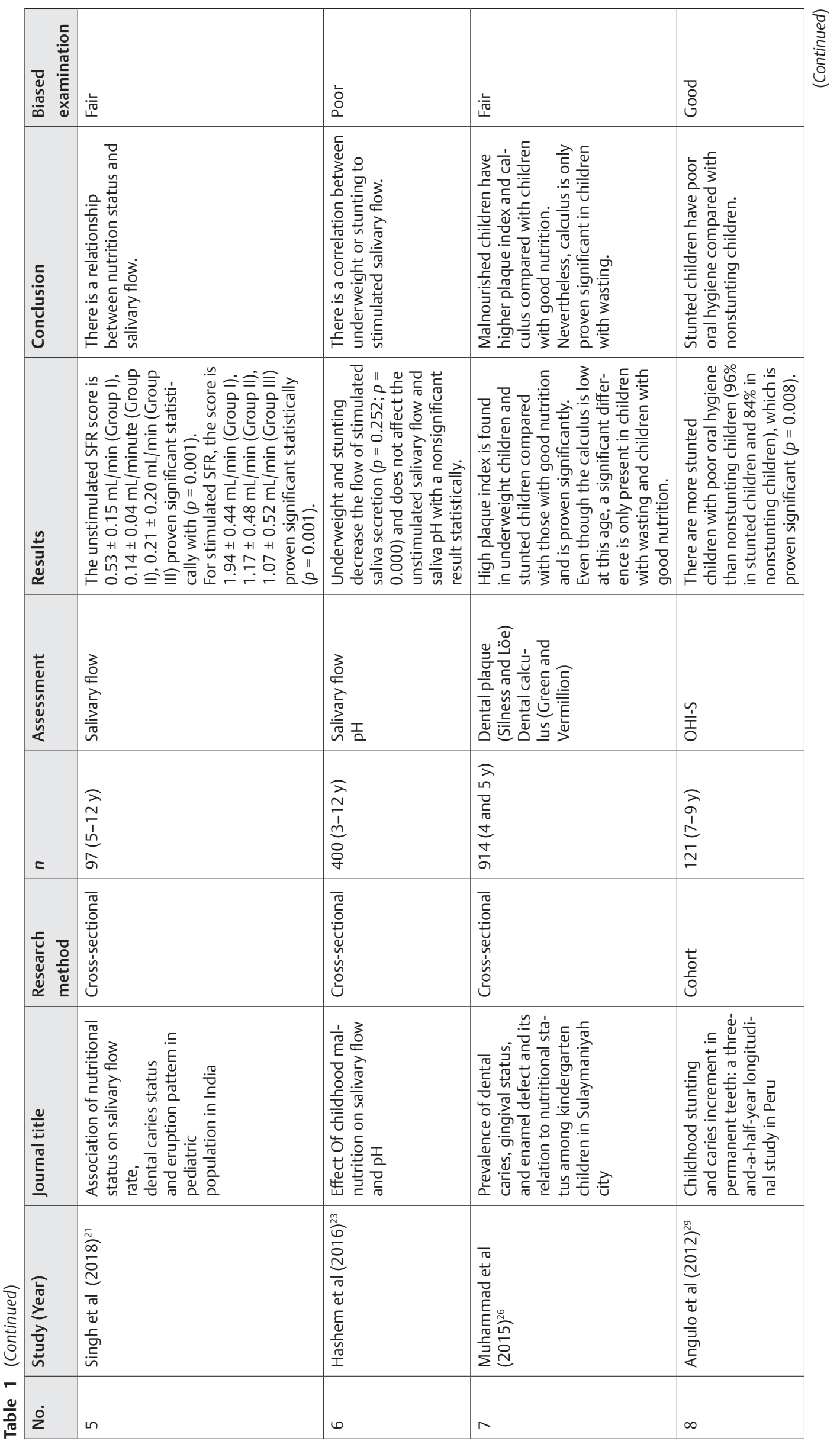


Stunting and Oral Health in Children Sadida et al. 37

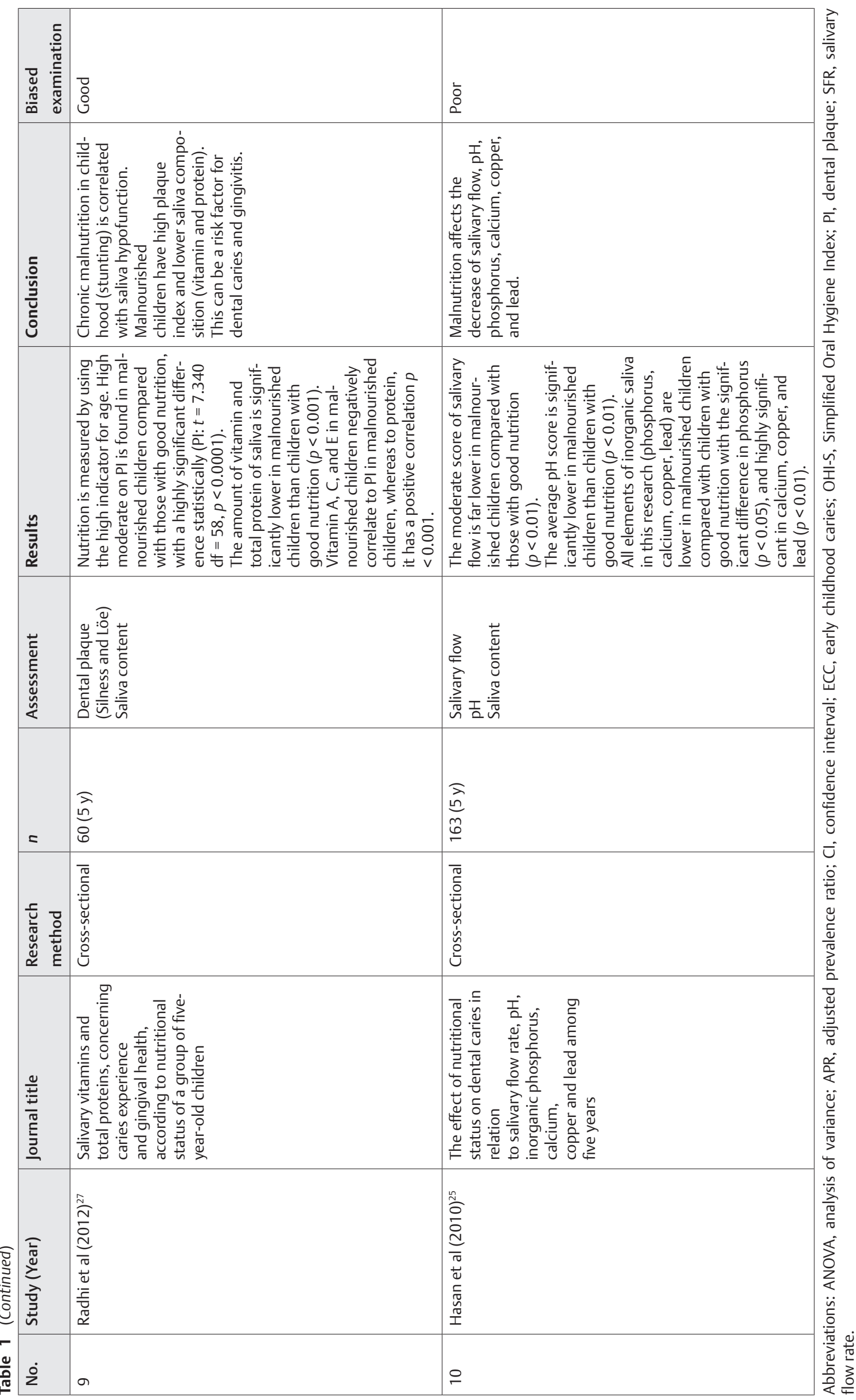


was defined by the finding of oral hygiene, oral disease (dental caries), salivary flow rate, and content. Oral hygiene was measured by using OHI-S by three authors. ${ }^{24,33,34}$ The study by Angulo et al (2012) stated that poor oral hygiene was higher in stunted children (96\%) than healthy children (84\%). ${ }^{33}$ Other studies revealed that in 25 children with growth stunting, 24 of them have poor oral hygiene as the remaining with a moderate level. ${ }^{24} \mathrm{~A}$ different matter was stated by Folayan et al in 2019 that associated stunting with early childhood caries (ECC) and related oral hygiene. Stunting is one of the risk factors for ECC. Of all the samples, there were no children with poor oral hygiene. So this study links stunting with ECC and moderate oral hygiene. ${ }^{34}$ Plaque and calculus examination by Muhammad et al (2015) in his study revealed that a high plaque index was found in children with growth stunting compared to the well-nourished group, and this is significant. Meanwhile, the calculus index in this study was still shallow and only proved significant for the wasted category. ${ }^{26} \mathrm{~A}$ high mean plaque index was also found in children with growth stunting compared to well-nourished children in the study of Radhi et al (2012) with a statistically very significant difference. ${ }^{27}$

Since Saliva plays a vital role in maintaining oral health and functions, ${ }^{35}$ the condition of moderate to poor oral health in stunted children can be caused by the hypofunction of the salivary glands, which is associated with a lack of nutrition in children. Hypofunction in the salivary glands can cause a decrease in salivary flow rate, reduced buffer capacity, and decreased composition of the Saliva. ${ }^{33}$ In good conditions, these salivary protective functions can help the clean surface of the teeth, one of which is from bacteria that accumulate in plaque food debris. ${ }^{36}$ Singh et al, in a 2018 study about salivary flow rates, revealed a decrease in stimulated and unstimulated salivary flow rate in children with growth stunting compared to well-nourished children. ${ }^{21}$ Other studies also showed the same thing because there was a negative correlation between salivary flow rate and nutritional status. This negative correlation means that a decrease in salivary flow occurs with a worsening child's malnutrition. ${ }^{22} \mathrm{~A}$ similar statement is also stated by Hasan et al, with his study shows a moderate value of salivary flow rate in children with growth stunting was much lower than that of well-nourished children. ${ }^{31}$ Meanwhile, Hashem et al (2016) have different results from Singh et al. In their study, growth stunting reduces the stimulated salivary flow rate and has no effect on the unstimulated salivary flow rate. ${ }^{23}$

In chronic malnutrition, which reflects growth stunting, the flow rate of saliva tends to decrease, leading to disruption of the protective function of Saliva in the oral cavity. This may reduce the ability of the oral cavity to withstand infection and the acid-buffering capacity of plaque that is directly related to caries. ${ }^{22}$ Regarding the study results by Hashem et al, where the unstimulated salivary flow rate was found not to affect, this could be due to changes in the weight of the parotid glands and decreased density of $\beta$-adrenoceptors. The parotid glands account for $50 \%$ of stimulated saliva secretion and only $20 \%$ for unstimulated Saliva. ${ }^{37}$ Also, Hashem's study was of a poor quality allowing a high potential for bias.
The pH test of saliva by Hashem et al and Hasan et al showed different results. Hashem stated that the $\mathrm{pH}$ of saliva in children with growth stunting was not affected, while Hasan stated that the mean $\mathrm{pH}$ value was significantly lower in stunted children than in well-nourished children. ${ }^{23,31}$ Saliva has an essential role in maintaining normal $\mathrm{pH}$ in the oral cavity and plaque. ${ }^{38}$ The change in $\mathrm{pH}$ of dental plaque will occur after food is consumed; a decrease in pH below the critical value will lead to demineralization of the tooth surface, leading to caries formation. ${ }^{39}$ However, there was a drawback to the two studies reviewed, both of which had poor journal quality or allowed a high potential for bias.

Apart from examining the $\mathrm{pH}$ of saliva, Hasan et al also examined the inorganic content of saliva, which was phosphorus, calcium, copper, and lead. ${ }^{31}$ The calcium and phosphorus content of Saliva can diffuse in a tooth and increase tooth resistance to caries. Calcium content can also be part of the formation of plaque consistency and affects the mineralization and demineralization process. ${ }^{38}$ In Hasan's study, all inorganic salivary elements in this study (phosphorus, calcium, copper, and lead) were lower in the malnutrition group than in the fantastic nutrition group, if significant differences phosphorus and highly significant for calcium, copper, and lead. ${ }^{31}$

Vitamins A, C, E, and total protein, such as other content of saliva, were investigated by Radhi et al. The results showed that the value of vitamins and total salivary protein was significantly lower in malnourished children than in well-nourished children. Vitamins A, C, and E in malnourished children negatively correlated with the plaque index, while protein positively correlates with the plaque index. ${ }^{27}$ The antioxidant system of saliva plays a vital role in building resistance and caries' susceptibility due to its free radical scavenging action. Also, the vitamins studied in this study affect the oxidative metabolism of carbohydrates in plaque to affect the metabolism of bacteria, which can lead to cell death. ${ }^{27}$ Thus, a decrease in vitamins may allow reduced salivary functions. Protein in Saliva also has a multifunctional role because it can work for the host as well as against the host. In connection with the results of the presentation of Radhi's research, which states that protein and plaque have a positive correlation, this can be due to the function of proteins that play a role in the adhesion process of microbes. This microbial adhesion process initiates the development of pathogenic plaques. ${ }^{40}$

The results of the above studies are in line with the review conducted by Achmad et al. The conclusion retrieved from various previous articles was that there was a relationship between dental conditions and stunting in children. Malnourished children have atrophic salivary glands that reduce salivary secretion and interfere with saliva's function to buffer and cleanse the oral cavity.

\section{Conclusion}

Based on the description above, it can be concluded that there is a correlation between growth stunting and oral health in children. This can be seen through the oral 
hygiene categorizing as moderate-poor through the OHI-S examination and the high plaque index found in selected studies. Also, it was found that there was a decrease in salivary flow rate and the composition of saliva in children with growth stunting. Dental caries is the most common contributor to oral disease, which implies decreased oral health and is correlated in children with growth stunting.

\section{Authors' Contributions}

All people who meet authorship criteria are listed as authors, and all authors certify that they have participated in all the parts of the realization of the manuscript. A.S.S. conceived the ideas. A.S.S., R.I., and Z.J.S. collected and analyzed the data. A.S.S. and Z.J.S. contributed to drafting the manuscript. A.S.S. finalized the writing of the manuscript.

\section{Funding}

This study was funded by Universitas Padjadjaran Academic Leadership Grant for fiscal year 2020 as funding source.

\section{Conflict of Interest}

None declared.

\section{Acknowledgments}

The authors wish to thank Universitas Padjadjaran for the Academic Leadership Grant and Dr. Dudi Aripin and Dr. Netty for reviewing this article during the mini-thesis defense.

\section{References}

1 Rohanawati RD, Bachtiar A. Effect of dental and oral health in underweight children under 5 years of age for stunting prevention: a systematic review. In: International Conference on Public Health. Solo: Universitas Sebelas Maret;209-218. Available at: http://theicph.com/wp-content/uploads/2019/07/37.-Rusmiati-Dwi-Rohanawati.pdf. Accessed 2019

2 Organization WH, Nutrition Landacape Information System (NLIS) Country Profile Indicators: Interpretation Guide. Nutrition Landacape Information System (NLIS). World Health Organization; 2019 1-51

3 Das S, Hossain MZ, Nesa MK. Levels and trends in child malnutrition in Bangladesh. Asia Pac Popul J 2009;24(2):51-78

4 Nathan AJ, Scobell A, How China sees America, Vol. 91. Foreign Affairs; 2012

5 Pantaleon MG, Hadi H, Gamayanti IL. Stunting berhubungan dengan perkembangan motorik anak di Kecamatan Sedayu, Bantul, Yogyakarta. J Gizi dan Diet Indones 2016;3(1):10

6 Sheetal A, Hiremath VK, Patil AG, Sajjansetty S, Kumar SR. Malnutrition and its oral outcome - a review. J Clin Diagn Res 2013;7(1):178-180

7 Achmad H, Ramadany S, Fajriani, et al. A review of stunting growth in children: relationship to the incidence of dental caries and its handling in children. Syst Rev Pharm 2020;11(6):230-235

8 Husain Akbar F, Pratiwi R, Sri Naca Hardiana AN. Oral hygiene and oral health related quality of life of children with stunting in Indonesia. Int J Dent Oral Sci 2020;7(1):711-717

9 Shaghaghian S, Zeraatkar M. Factors affecting oral hygiene and tooth brushing in preschool children, Shiraz/Iran. J Dent Biomater 2017;4(2):394-402
10 Kemenkes RI, Hasil Utama Riset Kesehatan Dasar Tahun 2018. Kementrian Kesehat Republik Indones; 2018

11 Mahmoodi P, Salimi P, Ashtiyani RD, Valaii N, Azarshab M, Shafizadeh N. Assessment of fine motor skills snd tooth brushing skills in 5-6 year olds in Tehran. Restor Dent Sci 2014;11(3):176-181

12 Newman MG, Tahei H, Klokkevold PR, Carranza FA, Newman and Carranza's Clinical Periodontology. 13th edition 2018. Vol. 1. Saunders; 2019

13 Kaur S, Soni S, Prashar A, Bansal N, Brar JS, Kaur M. Clinical and radiographic evaluation of autogenous dentin graft and demineralized freeze-dried bone allograft with chorion membrane in the treatment of grade II and III furcation defects: a randomized controlled trial. Indian J Dent Sci 2019;11(2):10-13

14 Aromataris E, Pearson A. The systematic review: an overview. Am J Nurs 2014;114(3):53-58

15 Dhammi IK, Haq RU. How to write systematic review or meta-analysis. Vol. 52. Indian J Orthop 2018;52(6):575-577

16 Adams J, Hillier-Brown FC, Moore HJ, et al. Searching and synthesising 'grey literature' and 'grey information' in public health: critical reflections on three case studies. Syst Rev 2016;5(1):164

17 MacDonald J. Systematic approaches to a successful literature review. J Can Health Libr Assoc 2014;34(1):46

18 Ma LL, Wang YY, Yang ZH, Huang D, Weng H, Zeng XT. Methodological quality (risk of bias) assessment tools for primary and secondary medical studies: what are they and which is better? Mil Med Res 2020;7(1):7

19 National Heart. Lung and BI. Significance of quality rating of good, fair, or poor [internet]. National Institute of Health. Available at: https://www.nhlbi.nih.gov/node/80102. Accessed 2014

20 Folayan MO, Arije O, El Tantawi M, et al. Association between early childhood caries and malnutrition in a sub-urban population in Nigeria. BMC Pediatr 2019;19(1):433

21 Singh N, Bansal K, Chopra R. Kaur Dharmani C. Association of nutritional status on salivary flow rate, dental caries status and eruption pattern in pediatric population in India. Indian J Dent Sci 2018;10(2):72-82

22 Vieira KA, Rosa-Júnior LS, Souza MAV, Santos NB, Florêncio TMM, Bussadori SK. Chronic malnutrition and oral health status in children aged 1 to 5 years: an observational study. Medicine (Baltimore) 2020;99(18):e19595

23 Hashem D, El-Bayoumy S, Fahmy W. El Malt M. Effect of childhood malnutrition on salivary flow and $\mathrm{pH}$. Al-Azhar Dent J Girls 2016;3(2):141-145

24 Vargas-Palomino KE, Chipana-Herquinio CR, Arriola-Guillén LE. [Oral health and oral hygiene conditions and nutritional status in children attending a health facility in the Huánuco Region, Peru]. Rev Peru Med Exp Salud Publica 2019;36(4):653-657

25 Hasan ZS, Diab BS. The effect of nutritional status on dental caries in relation to salivary flow rate, $\mathrm{pH}$, inorganic phosphorus, calcium, copper and lead among five years old kindergarten children. J Bagh Coll Dent 2010;22(3):119-122

26 Omer Muhammad N, Ali Al-Obaidi D, Mohammad Amen D. Prevalence of dental caries, gingival status, and enamel defect and its relation to nutritional status among kindergarten children in Sulaimani city. IOSR J Dent Med Sci Ver II 2015;14(12):2279-2861

27 Radhi NJ. Salivary vitamins and total proteins, in relation to caries-experience and gingival health, according to nutritional status of a group of five-year old children. J Baghdad Coll Dent 2012;24(3):129-136

28 Achmad H, Handayani H, Singgih MF, et al. Analysis of dental caries \& gingivitis with the occurrence of stunting in children in Makassar city (Tamalanrea subdistrict). Syst Rev Pharm 2020;11(4):371-376 
29 Delgado-Angulo EK, Hobdell MH, Bernabé E. Childhood stunting and caries increment in permanent teeth: a three and a half year longitudinal study in Peru. Int J Paediatr Dent 2013;23(2):101-109

30 Abdeshahi SK, Hashemipour MA, Mesgarzadeh V. Shahidi Payam A, Halaj Monfared A. Effect of hypnosis on induction of local anaesthesia, pain perception, control of haemorrhage and anxiety during extraction of third molars: a case-control study. J Craniomaxillofac Surg 2013;41(4):310-315

31 Hasan ZS, Diab BS, The effect of nutritional status on gingival health condition in relation to salivary zinc, magnesium, sodium and potassium among five years old kindergarten children. J Bagh Coll Dent 2010;22(3):87-90

32 Folayan MO, El Tantawi M, Schroth RJ, et al; Early Childhood Caries Advocacy Group. Associations between early childhood caries, malnutrition and anemia: a global perspective. BMC Nutr 2020;6(16):16

33 Delgado-Angulo EK, Hobdell MH, Bernabé E. Childhood stunting and caries increment in permanent teeth: a three and a half year longitudinal study in Peru. Int J Paediatr Dent 2013;23(2):101-109

34 Folayan MO, Oginni AB, El Tantawi M, Alade M, Adeniyi AA, Finlayson TL. Association between nutritional status and early childhood caries risk profile in a suburban Nigeria community. Int J Paediatr Dent 2020;30(6):798-804

35 Sruthi KS, Yashoda R, Manjunath P. Association between oral health status and salivary flow rate among individuals with and without burning mouth: a case control study. J Od Indian Assoc Public Heal Dent 2020;18(1):47-53

36 Andi Palancoi N. Hubungan antara pengetahuan dan lingkungan dengan kejadian diare akut pada anak di Kelurahan Pabbundukang Kecamatan Pangkajene Kabupaten Pangkep. J Kesehat 2014;7(2):346-352

37 Hassan DM, Hussien B. Oral health status in relation to nutritional status among kindergarten children aged (4-5) years old in Karbala city / Iraq. Mustansiria Dent J 2019;14(1):72

38 Roblegg E, Alanna Coughran DS. The composition, function and role of saliva in maintaining oral health: a review. Int J Contemp Dent Med Rev 2019;2017(1):133-141

39 Lin YJ, Lin YT. Influence of dental plaque $\mathrm{pH}$ on caries status and salivary microflora in children following comprehensive dental care under general anesthesia. J Dent Sci 2018;13(1):8-12

40 Laputková G, Schwartzová V, Bánovčin J, Alexovič M, Sabo J. Salivary protein roles in oral health and as predictors of caries risk. Vol. 13. Open Life Sci 2018;13:174-200 